\title{
Peningkatan kemampuan instructional leadership guru berbasis action learning di sekolah dasar
}

\author{
Sulastri Sulastri ${ }^{1}$, Syahril Syahri1 ${ }^{\left.1^{*}\right)}$, and Nelfia Adi $^{1}$ \\ ${ }^{1}$ Universitas Negeri Padang
}

\begin{tabular}{l} 
Article Info \\
\hline Article history: \\
Received May $18^{\text {th }}, 2021$ \\
Revised Jun $19^{\text {th }}, 2021$ \\
Accepted Jul $29^{\text {th }}, 2021$
\end{tabular}

\section{Kata Kunci:}

Instructional

Leadership

Guru

Action Learning

\begin{abstract}
ABSTRAK
Kegiatan pengabdian masyarakat dilatar belakangi oleh kurang maksimalnya instructional leadership guru di lapangan. Adapun tujuan dari kegiatan pengabdian kepada masyarakat ini adalah untuk; 1) meningkatkan pemahaman dan pengetahuan guru tentang instructional leadership berbasis Action Learning , 2) mempersiapkan guru-guru agar mampu menghadapi setiap permasalahan yang terjadi di lapangan, 3) memberikan keterampilan dan meningkatkan kualitas pembelajaran dimasa pandemi COVID 19, 4) melatih guru-guru dalam menyelesaikan permasalahan yang berbasis action learning (menganalisis situasi dan kondisi nyata, melibatkan tim, melakukan deep interview dan refleksi, merumuskan action, dan melaksanakan action), 5) melatih dan meningkatkan kemampuan guru-guru dalam berpikir kritis (critical thinking). Berdasarkan kegiatan yang telah dilaksanakan di peroleh respon positif, hal ini terlihat dari tingginya antusias guru-guru dalam pelaksanaan kegiatan tersebut. Langkah pertama yang dilakukan ialah guru diminta untuk mengidentifikasi permasalahan yang terjadi di lapangan sehubungan dengan instructional leadership. Kemudian guru diberikan pemahaman tentang materimateri dan permasalahan yang dihadapinya. Sebagai umpan balik dari pihak Koordinator Pendidikan dan guru sekolah dasar, bahwa mereka bersedia menjadi sekolah binaan untuk berbagai kegiatan peningkatan kualitas pendidikan. Harapan dari pihak Koordinator Pendidikan Kecamatan Tilatang Kamang dan guru-guru yang ada di Sekolah Dasar, prestasi sekolah terus mengalami peningkatan seiring dengan adanya kerjasama dengan Universitas Negeri Padang.
\end{abstract}

(C) 2021 The Authors. Published by IICET

This is an open access article under the CC BY-NC-SA license (https://creativecommons.org/licenses/by-nc-sa/4.0)

\section{Corresponding Author:}

Syahril Syahril

Universitas Negeri Padang

Email: syahril@fip.unp.ac.id

\section{Pendahuluan}

Peningkatan mutu pendidikan perlu dilakukan secara berkesinambungan. Para pemangku kepentingan harus bekerjasama dengan maksimal untuk peningkatan mutu pendidikan dalam rangka mencapai tujuan pendidikan yang diinginkan. Sebagai mana yang dikemukakan dalam Undang-undang Nomor 20 Tahun 2003, bahwa tujuan pendidikan nasional adalah untuk mengembangkan potensi peserta didik agar mereka menjadi manusia yang beriman dan bertakwa kepada Tuhan Yang Maha Esa, berakhlak, cakap dan kreatif serta bertanggung jawab. Untuk itu pemerintah, stakeholder, masyarakat dan sekolah perlu bekerjasama untuk menyusun berbagai program peningkatan mutu pendidikan. 
Sekolah perlu bekerja dengan lebih ekstra untuk meningkatkan prestasi sekolahnya. Kepala sekolah dan guru harus saling berkolaborasi untuk menghasilkan mutu pembelajaran terutama dalam instructional leadership, Liu \& Low (2015). Tanpa kolaborasi guru dan kepala sekolah mustahil tujuan pembelajaran tercapai dengan maksimal. Dalam hal ini kepala sekolah dan guru saling mengisi, guru dan kepala sekolah saling memahami apa yang menjadi tugas pokok dan fungsi mereka terutama dalam menjalankan instructional leadership. Instructional leadership yang terkelola dengan baik akan menghasilkan prestasi baik untuk guru, kepala sekolah dan yang lebih penting lagi adalah prestasi siswa. Guru sebagai salah satu orang yang melaksanakan instructional leadership harus meningkatkan perannya dalam membimbing serta memberikan arahan, memotivasi siswa dalam berbagai situasi pembelajaran serta melakukan kolaborasi dengan berbagai unsur sekolah, Bhayangkara et al. (2020), Utari \& Widodo (2018), Boonying (2012), Sherman et al. (2007), Gumus \& Akcaoglu (2013).

Kemampuan instructional leadership guru dapat dilakukan dengan memberikan bimbingan pembelajaran, mengkomunikasikan arah kegiatan pembelajaran, menciptakan lingkungan pembelajaran yang kondusif, Bamburg and Andrews (1990). Selain itu, guru dapat menjalankan instructional leadership dengan melatih berbagai kemampuan pembelajaran dengan melakukan penyaringan, persiapan dan induksi dalam menjalankan kurikulum. Lebih lanjut juga diperlukan pengalaman, kemampuan berpikir logika dan jiwa inovasi, Taylor Backor and Gordon (2015), Ayatollah (2020), Ismail et al., (2018), (Rigby, 2014).

Agar kemampuan instrukctional leadership guru dapat meningkat maka perlu dilakukan semacam pembinaan ataupun pelatihan dalam mengatasi berbagai permasalahan nyata yang dihadapi guru. Semua permasalahan instructional leadership guru dapat diatasi dengan baik, bila dipahami langkah-langkah pemecahan masalah. Revans (2016) menawarkan alternatif pemecahan masalah dengan action based learning, yang terdiri dari; 1) kemampuan untuk memahami situasi pembelajaran. Pemahaman situasi didasarkan dengan melakukan analisis SWOT yaitu Strangh, Weakness, Opportunity, dan Treath. 2) kemampuan untuk melibatkan rekan kerja atau tim dalam mengidentifikasi dan melakukan refleksi dari kegiatan pembelajaran yang telah dilakukan, 3) kemampuan untuk melakukan deep interview. Hal ini penting untuk mengetahui secara mendalam permasalahan pembelajaran yang dihadapi. 4) Kemampuan guru dalam merumuskan berbagai action atau tindakan yang perlu dilakukan. 5) Kemampuan guru untuk melaksanakan action tersebut. 6) Kemampuan untuk mengevaluasi action yang telah dirumuskan.

Kecamatan Tilatang Kamang Kabupaten Agam, juga selalu berusaha meningkatkan mutu pendidikan. Namun, sejak situasi dan kondisi Pandemi Covid 19 banyak kegiatan yang tidak terealisasi dengan baik. Salah satu yang berdampak sekarang ini adalah menurunnya kemampuan professional guru dalam instructional leadership. Tercatat ada 26 SD Negeri dan 2 SD Swasta, 8 SMP, 2 SMA, 5 MA, SMK 1. Dulunya kecamatan Tilatang Kamang terdiri dari 7 kecamatan yaitu Palupuh, Gadut, Koto Tangah, Kapau, Magek, Kamang Hilir, dan Kamang Mudik. Namun sejak ada pemekaran wilayah, terbentuk kecamatan baru yaitu Palupuh dan Kamang Magek, sehingga Kecamatan Tilatang Kamang terdiri dari 3 kenagarian yaitu Gadut, Koto Tangah dan Kapau.

Berdasarkan wawancara dilakukan pada awal Maret 2021 dengan petugas Koordinator Pendidikan Unit Kerja Kecamatan Tilatang Kamang Kabupaten Agam dengan Bapak Iskandar, S.Pd., M.H., terlihat menurunnya kualitas instructional leadership guru. Data dari pegawai Koordinator Pendidikan tercatat semenjak tahun 2019 bisa dikatakan $0,0 \%$ tidak ada kegiatan yang dilakukan secara khusus untuk memberikan penyegaran dan peningkatan kompetensi professional guru terutama dalam hal instructional leadership. Hanya tergantung inisiatif guru-guru saja dengan kegiatan lepas yang dicari pada media lainnya. Selain itu, penulis juga melakukan wawancara dengan guru dan orang tua terkait proses pembelajaran yang dilakukan beberapa tahun terakhir dan juga terkait dengan kondisi pandemi Covid 19. Secara rinci dapat dijelaskan permasalahan yang terjadi sebagai berikut: 1) Guru kurang maksimal dalam merancang pembelajaran baik secara luring ataupun daring. Keadaan ini juga didukung kondisi di pedesaan yang mana masyarakat masih belum begitu mampu menggunakan ataupun memiliki fasilitas untuk pembelajaran daring. Hal ini menyebabkan komunikasi pembelajaran kurang berjalan dengan maksimal. 2) Guru kurang mampu memberikan bimbingan dan arahan kepada siswa dalam memahami mata pelajaran. Sehingga cenderung tugas-tugas yang dikerjakan anak tidak bisa dikerjakan anak, kalaupun mereka kerjakan itupun orang tua mereka yang mengerjakannnya. Seharusnya guru bisa melakukan bimbingan dengan berbagai metode seperti mendatangkan siswa ke sekolah dengan mematuhi protokol Kesehatan. 3) Kurangnya analisis guru dalam menerapkan strategi pembelajaran, mendesain pembelajaran, menganalis pembelajaran serta mengevaluasi pembelajaran. Kalau guru kurang maksimal melakukan ini, maka tingkat pemahaman anak akan semakin sulit dicapai. 4) Terlihat guru juga masih kesulitan dalam mengembangkan kurikulum, hal ini terlihat kurangnya best activity yang dilakukan guru. Padahal untuk anak sekolah dasar harus banyak best activity yang dilakukan guru dalam membangkitkan kreativitas dan daya inovasi siswa. Di dalam kelas sangat minim sekali diperlihatkan hasil karya siswa yang 
berdasarkan prinsip best activity. 4) Terlihat guru-guru masih kurang maksimal dalam menggunakan dan memanfaatkan sarana dan prasarana pembelajaran. Padahal sarana dan prasarana pembejaran merupakan unsur terpenting untuk meningkatkan prestasi anak. 5) Iklim pembelajaran yang kondusif juga tidak terlaksana dengan baik, hal ini terlihat dari ketidakpahaman siswa dalam memahami mata pelajaran, dan mereka kesulitan untuk bertanya serta melakukan komunikasi dengan guru. Sehingga banyak dari peserta didik yang kebingungan dalam mengerjakan tugas, bahkan ada siswa yang tidak mengerjakan. Selain itu juga disebabkan, keterbatasan pengetahuan orang tua tentang cara mengajar dan memberikan pemahaman pada anak

\section{Metode}

Kegiatan pengabdian ini dilakukan secara daring dan luring. Secara daring dilakukan dengan memberikan kegiatan mandiri selama lima hari pada guru-guru terhadap bidang kegiatan pengabdian yang dilakukan yaitu tentang instructional leadership dalam hal konsep tentang instructional leadership guru, pengelolaan pembelajaran dan iklim kelas yang kondusif, penggunaan media pembelajaran berbasis Information Technologi (IT) dan penilaian pembelajaran berbasis IT. Lebih lanjut, kegiatan pengabdian ini dilakukan secara luring dengan mengadakan pelatihan langsung di Kecamatan Tilatang Kamang, tepatnya di Sekolah Dasar Negeri 11 Gadut. Setelah kegiatan pengabdian kami melakukan wawancara dengan pihak Koordinator Unit Kerja Tilatang Kamang, untuk keberlanjutan kegiatan selanjutnya. Selain dengan pihak Koordinator Unit Kerja Tilatang Kamang, juga dilakukan wawancara dari 33 orang yang hadir disaat pelatihan. Dimana mereka menyambut baik dan ingin ada kegiatan lanjutan untuk meningkatkan kompetensi mereka. Sehubungan situasi dan kondisi pandemi Covid 19 dan Kecamatan Tilatang Kamang ini termasuk zona hijau, jadi peneliti dapat melakukan kunjungan langsung dengan tetap mematuhi protokol kesehatan. Berikut tahapan yang dilakukan yaitu, 1) persiapan, 2) pelaksanaan, 3) evaluasi, 4)

\section{Hasil dan Pembahasan}

Pelaksanaan kegiatan pengabdian kepada masyarakat yang bertemakan peningkatkan kemampuan instructional leadership guru berbasis action learning di sekolah dasar Kecamatan Tilatang Kamang Kabupaten Agam. Kegiatan ini dilaksanakan 5 hari kegiatan mandiri dan 2 hari kegiatan pelatihan langsung pada tanggal 31 Juli dan 1 Agustus 2021 yang bertempat di SD Negeri 11 Gadut Kecamatan Tilatang Kamang. Para peserta merupakan guru sekolah dasar Kota di Kecamatan Tilatang Kamang Kabupaten Agam. Jumlah guru sekolah dasar yang mengikuti kegiatan ini berjumlah 30 orang dan kegiatan dilaksanakan sesuai protokol kesehatan pada masa pandemi Covid 19.

Berdasarkan presentase kehadiran, semua peserta hadir dalam kegiatan. Namun seiring berjalannya kegiatan, masih ada peserta yang berasal dari sekolah lain yang mengikuti kegiatan dan mengisi daftar kehadiran berjumlah 3 orang, sehingga keseluruhan peserta yang mengikuti kegiatan tersebut berjumlah 33 orang. Selama kegiatan pelatihan berlangsung para peserta sangat antusias dalam bertanya, serius dan sangat bersemangat dalam mengikuti kegiatan.

Pertama kali kegiatan pelatihan dilakukan dengan memberikan pemahaman tentang materi tentang kepemimpinan pembelajaran guru oleh Drs. Syahril, M. Pd., Ph. D. Pemberian materi semakin menarik ketika para peserta mengetahui bagaimana betul kepemimpinan pembelajaran yang berbasis action learning itu. Bahkan di sini mereka sangat terkesan dengan sintaks dari kegiatan action learning yaitu: 1) Menganalisis situasi dan kondisi baik kondisi internal dan kondisi eksternal; 2) Melibatkan tim dalam penyelesaian masalah; 3) Melakukan deep interview dan refleksi; 4) Merumuskan action; 5) Melaksanakan action; 6) Mengevaluasi action

Oleh karena itu guru-guru semakin antusias untuk menyelesaikan semua permasalahannya sebaik mungkin dengan mengidentifikasi permasalahan yang ada proses critical thinking yang baik di dalamnya, yang membuat guru-guru terlatih untuk bisa merumuskan action yang tepat dalam setiap permasalahan serta melaksanakan action tersebut dengan baik. Kemudian para peserta sangat antusias bertanya terkait masalah yang mereka hadapi di sekolah yang sangat kompleks dan bervariasi sehingga mendapatkan solusi untuk diambil action-nya.

Begitupun untuk materi berikutnya yaitu tentang penggunaan media pembelajaran berbasis IT yang disampaikan oleh Dr. Ulfia Rahmi, M.Pd., juga sangat menarik. Apalagi Ibu Dr. Ulfia Rahmi, M. Pd., orang yang sudah banyak sekali pengetahuan lapangannya tentang media-media dalam pembelajaran yang berbasis IT. Guru sekolah dasar juga melakukan berbagai sharing permasalahan untuk dipecahkan bersama-sama dalam sesi tanya jawab. 
Tidak kalah menarik materi yang tentang Pengelolaan Pembelajaran dan Iklim Kelas yang Kondusif yang disampaikan oleh Bapak Dr. Irsyad, M.Pd. penyampaian materi dilakukan sangat baik dan menyenangkan diselingi dengan candaan yang mengarah pada materi, sehingga dengan mudah peserta dapat memahami materi yang disampaikan

Terakhir materi yang disampaikan oleh Bapak Dr. Ahmad Sabandi, M,Pd., yaitu materi tentang penilaian pembelajaran berbasis IT yang memfokuskan pada penggunaan game edukasi yaitu Quiziz dalam penilaian pembelajaran berbasis IT. Materi ini sangat penting, karena siswa dapat belajar sekalipun bermain (game) dalam proses maupun penilaian pembelajaran sehingga menghilangkan kejenuhan dalam proses pembelajaran.

Bila dilihat dari tanya jawab dan diskusi selama kegiatan pengabdian yang dilakukan sekitar $85 \%$ kegiatan pelatihan ini tercapai dengan baik. Dimana kegiatan ini sangat memberikan pengalaman serta pencerahan terhadap guru-guru yang ada di sekolah dasar khususnya dalam hal kepemimpinan pembelajaran berbasis Action Learning. Sehingga sangat diharapkan kemampuan kepemimpinan mereka dapat meningkat dan lebih optimal lagi.

\section{Instructional leadership guru berbasis action learning}

Kegiatan pengabdian masyarakat ini memberikan bekal bagi guru-guru yang ada di Sekolah Dasar untuk memimpin pembelajaran dengan baik. Khususnya dalam hal kepemimpinan pembelajaran berbasis action learning sehingga mampu mengantarkan guru, siswa dan sekolah yang berprestasi menuju sekolah unggul. Pelaksanaan pelatihan ini sangat menarik karena materi disesuaikan dengan analisis kebutuhan guru-guru di lapangan yang telah diidentifikasi sebelumnya, sehingga peserta sangat antusias dalam mengikutinya.

Guru sebagai pemimpin di dalam kelas, dapat dikatakan berhasil apabila telah menerapkan karakter sukses menjadi seorang pemimpin. Seperti yang dikemukakan oleh Carnegie (2015) yaitu: 1) Guru harus menanamkani nilai-nilai dan etika yang kuat dan tinggi; 2) Guru menjadi teladan dalam bertindak dengan penuh integritas; 3) Guru memiliki pengetahuan dan tujuan instansi yang jelas; 4) Guru bersikap proaktif dan mampu meberikan motivasi yang baik; 5) Guru dapat mengontrol emosi; 6) Guru dapat bekerjasama dengan berbagai pihak yang berkaitan dengan diinstasinya; 7) Guru mampu memanajemen waktu dengan baik; 8) Guru harus inovatif dan punyanai visi yang jelas

Berdasarkan hasil evaluasi yang dilakukan dalam kegiatan pengabdian kepada masyarakat dengan judul "Peningkatan Kemampuan Instructional Leadership Guru Berbasis Action Learning Di Sekolah Dasar Kecamatan Tilatang Kamang Kabupaten Agam". Dapat ditarik kesimpulan bahwa guru-guru yang ada di Kecamatan Tilatang Kamang telah menguasai dan memahami berbagai materi yang diberikan. Dengan demikian diharapkan guru-guru dapat menerapkan diinstansi mereka apa yang telah dilatihkan kepada mereka dengan baik.

Selain itu, diharapkan sekali seluruh guru yang ada di Sekolah Dasar untuk selalu meningkatkan dan mengembangkan pengetahuannya dengan mengikuti berbagai kegiatan seperti seminar, pelatihan, dll dalam bentuk pendidikan. Karena untuk menjadi guru yang berkualitas tidak cukup dengan ilmu pengetahuan yang ada saja, melainkan harus digali dengan berbagai kegiatan.

Harapan dari seluruh pihak yang terlibat adalah agar kerjasama ini harus tetap terjalin dan dapat mengalami peningkatan, sehingga mampu menjadi motor penggerak dalam usaha memajukan pendidikan khususnya di Kecamatan Tilatang Kamang Kabupaten Agam.

\section{Peran Instructional Leadership guru.}

Guru sangat ditantang untuk mampu menerapkan kompetensi yang akan dicapai dalam hal kepemimpinan pembelajaran analisis kebutuhan pembelajaran, model implementasi serta kompetensi guru dalam memimpin pembelajaran. Goddard et al., (2015), Mattar (2012), Heck (1992), Kusumaningrum et al., (2020), Usman \& Raharjo (2013), Tanama et al., (2017) menegaskan bahwa melaksanakan kepemimpinan pembelajaran, guru dituntut untuk berperan serta dalam mengoptimalkan berbagai hal yaitu, merumuskan kurikulum tingkat satuan pelajaran, mengelola kurikulum dan sumberdaya untuk pembelajaran, memonitor perencanaan dan pelaksanaan pembelajaran dan terakhir mengevaluasi pelaksanaan tugas guru. Selain itu guru harus mampu berkolaborasi dalam melaksanakan kepemimpinan pembelajarannya. Muara akhir dari semua kegiatan yang dilakukan guru ini akan meningkatkan kinerjanya dan terwujudnya sekolah yang berprestasi.

Disisi lain kepala sekolah juga harus memperhatikan kepemimpinan pembelajaran guru agar mampu meningkatkan peran guru sehingga dapat menjadi fasilitator dalam mengembangkan prestasi siswa, meningkatkan kepuasan siswa, memotivasi siswa, meningkatkan rasa keingintahuan, membentuk kreativitas, inovasi, jiwa kewirausahaan, dan kesadaran untuk belajar sepanjang hayat. Apalagi dalam situasi pandemi Covid sekarang ini kepala sekolah dan guru selain berkolaborasi menentukan kebijakan dan manajemen yang 
baik dalam pembelajaran, perlu memiliki komitment yang tinggi agar pembelajaran bisa terlaksana dengan baik (Bush, 2021; Frye \& McCarron, 2021).

Pelatihan kepemimpinan pembelajaran berbasis action learning yang diberikan kepada guru-guru yang ada di Sekolah Dasar sangat menginspirasi guru-guru tersebut untuk dapat meningkatkan lagi kegiatan kepemimpinannya dalam pembelajaran. Oleh karena itu guru ditekankan untuk menguasai prinsip-prinsip kepemimpinan pembelajaran.

\section{Faktor Pendukung}

Beberapa faktor pendukung yang membuat kegiatan pengabdian kepada masyarakat terlaksana dengan baik, yaitu: 1) Guru-guru yang ada di Sekolah Dasar memiliki motivasi tinggi untuk kegiatan ini, hal ini dibuktikan dengan keaktifan mereka ketika kegiatan pelatihan diberikan; 2) Kerjasama dengan pihak Koordinator Pendidikan Kecamatan Tilatang Kamang terjalin dengan sangat baik, yang mana membantu dalam menghadirkan guru-guru yang ada di Sekolah Dasar dalam upaya peningkatan kompetensi guru Sekolah Dasar Kecamatan Tilatang Kamang; 3) Pemateri yang ahli dan sudah berpengalaman dalam bidang kepemimpinan pembelajaran, sehingga mampu memberikan solusi terbaik terhadap permasalahan yang dihadapai oleh guru-guru tersebut.

\section{Faktor Penghambat}

Sebenarnya waktu untuk kegiatan pengabdian kepada masyarakat terbilang cukup, namun guru-guru sangat menginginkan durasi waktunya ditambah lagi untuk peningkatan kompetensi guru yang lainnya. Namun terkendala dengan waktu dan faktor lainnya, sehingga kegiatan ini hanya dapat dilakukan dua hari saja, yaitu pada tanggal 31 Juli dan 1 Agustus 2021. Walaupun kita sudah menugaskan mereka sebelumnya yaitu dari tanggal 26-30 Juli 2021 secara mandiri dalam rangka memahami materi terkait kegiatan pengabdian kepada masyarakat dan mengidentifikasi berbagai permasalahan yang terjadi di lapangan untuk diangkat dan dipecahkan pada kegiatan utama. Namun durasi waktu ini masih perlu ditingkatkan agar informasi dan pendidikan dalam kepemimpinan ini lebih banyak diperoleh oleh guru. Semoga dilain waktu dan kesempatan hal ini bisa diwujudkan

\section{Simpulan}

Dapat disimpulkan kegiatan pengabdian kepada masyarakat yang mengangkat tema "Peningkatan Kemampuan Instructional Leadership Guru Berbasis Action Learning Di Sekolah Dasar Kecamatan Tilatang Kamang Kabupaten Agam" berjalan lancar. Guru sebagai peserta dalam kegiatan ini sangat bersemangat dalam mengikuti kegiatan. Terlihat dari antusiasnya guru dalam bertanya pada saat kegiatan berlangsung, karena kegiatan ini memberikan ilmu dan pengalaman bagi guru sekolah dasar agar dapat menyelesaikan masalah yang terjadi di lapangan,

\section{Referensi}

Ayatollah, H. (2020). Peran Kepala Sekolah dalam Pembelajaran Daring Era Revolusi 4.0. Di Akses Tanggal 22 April 2020.

Bhayangkara, A. N., Ahmadi, W. H., Firdaus, D. B., Prestiadi, D., \& Sumarsono, R. B. (2020). The Role of Instructional Leadership Through Kurt Lewin Model in Improving the Teacher Capability. 2nd Early Childhood and Primary Childhood Education (ECPE 2020), 307-317.

Boonying, V. (2012). Training Needs Policies Based on the Development of Leadership Competencies for Heads of Public Sectors in Thailand. International Journal of Arts \& Sciences, 5 (1) 297-506.

Bush, T. (2021). Leading through COVID-19: Managing a crisis. SAGE Publications Sage UK: London, England.

Carnegie, D. (2015). Petunjuk Hidup Tenteram dan Bahagia. PT. Gramedia Pustaka Utama.

Frye, S. L., \& McCarron, G. P. (2021). Leveraging High-Impact, Collaborative Learning in an Undergraduate Nonprofit Studies Course Toward Bolstering Career Readiness. The Journal of Nonprofit Education and Leadership, 11(2).

Goddard, R., Goddard, Y., Sook Kim, E., \& Miller, R. (2015). A theoretical and empirical analysis of the roles of instructional leadership, teacher collaboration, and collective efficacy beliefs in support of student learning. American Journal of Education, 121(4), 501-530.

Gumus, S., \& Akcaoglu, M. (2013). Instructional leadership in Turkish primary schools: An analysis of teachers' perceptions and current policy. Educational Management Administration \& Leadership, 41(3), 289-302. 
Heck, R. H. (1992). Principals' instructional leadership and school performance: Implications for policy development. Educational Evaluation and Policy Analysis, 14(1), 21-34.

Ismail, S. N., Don, Y., Husin, F., \& Khalid, R. (2018). Instructional Leadership and Teachers' Functional Competency across the 21st Century Learning. International Journal of Instruction, 11(3), 135-152.

Kusumaningrum, D. E., Sumarsono, R. B., \& Gunawan, I. (2020). Pengaruh Kepemimpinan Pembelajaran, Kepemimpinan Perubahan, Kepemimpinan Spiritual, Budaya Sekolah, dan Etika Profesi terhadap Kinerja Mengajar Guru. JMSP (Jurnal Manajemen Dan Supervisi Pendidikan), 4(3), 198-219.

Liu, W. C., \& Low, E. L. (2015). Editorial: Teacher Education for the 21 st Century . Educational Research for Policy and Practice, 189-191.

Mattar, D. (2012). Instructional leadership in Lebanese public schools. Educational Management Administration \& Leadership, 40(4), 509-531.

Revans, R. (2016). ABC of Action Learning. Routledge.

Rigby, J. G. (2014). Three Logics of Instructional Leadership. Educational Administration Quarterly, 50(4), 610-644. https://doi.org/10.1177/0013161X13509379

Sherman, R. O., Bishop, M., Eggenberger, T., \& Karden, R. (2007). Development of a Leadership Competency Model. JONA: The Journal of Nursing Administration, 37(2), 85-94. https://doi.org/10.1097/00005110-200702000-00011

Tanama, Y. J., Bafadal, I., \& Degeng, N. S. (2017). Pentingnya Kepemimpinan Pembelajaran di Sekolah. Prosiding Seminar Nasional Mahasiswa Kerjasama Direktorat Jenderal Guru Dan Tenaga Kependidikan Kemendikbud 2016.

Taylor Backor, K., \& Gordon, S. P. (2015). Preparing Principals as Instructional Leaders: Perceptions of University Faculty, Expert Principals, and Expert Teacher Leaders. NASSP Bulletin, 99(2), 105-126. https://doi.org/10.1177/0192636515587353

Usman, H., \& Raharjo, N. E. (2013). Strategi kepemimpinan pembelajaran menyongsong implementasi kurikulum 2013. Jurnal Cakrawala Pendidikan, 5(1).

Utari, R. A., \& Widodo, J. (2018). Pengaruh Kepemimpinan Instruksional Guru dan Fasilitas Kelas Terhadap Prestasi Belajar Siswa Melalui Motivasi Belajar. EEAJ Economic Education Analysis Journal, 7(3).Undang-undang Nomor 20 Tahun 2003. Sistem Pendidikan Nasional. RI

Willison, R. (2008). What Make an Instructional Leader dalam Phi Delta Kappan, Nov. 2010. 92(3), 66-69. 